\title{
Lupus Carditis
}

\author{
Creso A. Falcão, N orma Lucena, Izabel C. Alves, Ângela L. Pessoa, Emmanuelle T. Godoi
}

\author{
Recife, PE - Brazil
}

The kidney has usually been considered the most frequently affected organ in systemic lupus erythematosus, the heart and the pulmonary vessels, however, may also be seriously involved. The diagnosis of a cardiac lesion may be occasionally difficult due to the common coexistence of multiple clinical problems, such as renal failure and infection, in lupus patients. Nevertheless, the specific cardiac involvement (lupus carditis) requires suitable diagnosis because in most of the cases immunosupressive treatment must be added to conventional therapy. Pericarditis, myocarditis, Libman-Sacks endocarditis, pulmonary arterial hypertension and coronary artery disease are the main cardiovascular complications associated with autoimmune manifestations in systemic lupus erythematosus. The so-called "lupus anticoagulant" and the anticardiolipin antibodies, which are also often called antiphospholipid antibodies, have been associated different cardiac involvements in systemic lupus erythematosus.

Systemic lupus erythematosus (SLE) is an autoimmune disease of unknown origin characterized by inflammation of multiple organs (kidneys, brain, heart, liver, lungs, joints, muscles, skin, etc.) with an evolution that is punctuated by remission and recurrence. The severity of the disease is variable, ranging from light and superficial clinical evidence, such as involvement of the skin and arthritis, to quick fulminating forms with renal failure and serious disorders of the central nervous system ${ }^{1,2}$.

The name "lupus" comes from the Latin word "lupus", which means wolf and refers to the classic erythematosus ulceration of the face. Early medical observations of the disease that date back at least seven centuries describe lupus as "a sickness that corrodes, bites and destroys" ${ }^{3}$. Systemic lupus erythematosus is the most common of the autoimmune systemic diseases ${ }^{4}$ with an estimated prevalence of 4 - 250 cases in 100,000 individuals in the general population, and occurs more frequently in females in the 16 - 55 year age group ${ }^{5}$. The strongest, most characteristic aspect of SLE is its autoimmune status, characterized by the development of multiple antibodies derived from the nucleus, cytoplasm and cell membranes ${ }^{1,5}$.

Faculdade de Ciências Médicas - FESP - Universidade de Pernambuco Correspondência: Creso A. Falcão - Rua Padre Carapuceiro, 488/603 - 51020280 - Recife, PE - Brazil.

Received on $3 / 4 / 99$

Accepted on 5/19/99
The kidneys are still the most studied organs in lupus, with the outcome of renal lesions traditionally considered a mark of the evolution and prognosis of the patient involved. But it has been known for at least a century that the heart can also develop serious lesions and may contribute in an equally significant way to the morbidity and mortality of the illness ${ }^{6-8}$.

In clinical practice and even according to the relevant reports in the literature, it may ultimately be difficult to differentiate the cardiac involvement due to SLE from the one that occurs in SLE as a result of other causes ${ }^{9}$, such as arterial hypertension and infectious endocarditis. It is known, however, that cardiac involvement is the third most common cause of death in lupus, following infections and renal failure ${ }^{10}$. The aim of this report is to emphasize the cardiac disease considered specific to SLE, which occurs as a result of the autoimmune alterations caused by the disease. Cardiac involvement seems to be more easily detected during periods of activity of the illness ${ }^{11}$ and is more customarily referred to as lupic cardiopathy or lupic carditis (table I).

Since 1895, William Osler has been considered to be the first to recognise cardiac lesions, in addition to the other complications of the multiform exudative erythema also classified as inflammatory, such as cerebral, respiratory, gastrointestinal and renal involvement, as part of systemic lupus ${ }^{12,13}$. However Libman and Sacks focused attention on a form of cardiac involvement they considered specific to lupus. They reported post-mortem findings of a form of noninfectious endocarditis called atypical verrucous endocarditis in four patient with clinical data suggesting SLE ${ }^{14}$. Gross, from 1932 - 1940, described in detail the pathological findings of lupus carditis and concluded that the cardiac involvement of lupus was in fact a pancarditis ${ }^{15,16}$.

As a whole, the cardiac involvement in SLE is estimated to have a prevalence of $30-50 \%{ }^{17}$, or up to $52-80 \%$ when pulmonary hypertension is included ${ }^{8}$. Differences among several reports are probably due to the detection methods used. For example an approximate $57 \%$ frequency is found when two-dimensional echocardiography and Doppler are used ${ }^{12}$. Patients with SLE may simultaneously present with more than one form of heart disease.

In spite of the cardiac lesions considered specific to SLE that may presumably be due to the deposition of immune complexes in the pericardium, myocardium or vessel wall ${ }^{12}$, and of various studies aiming to define an asso- 


\begin{tabular}{|lcl|}
\hline \multicolumn{3}{|c|}{ Table I - Frequency of cardiac events in lupus } \\
\hline Cardiopathy & Frequency $(\%)$ & \multicolumn{1}{c|}{ Method } \\
\hline Pericarditis & $24-49$ & Doppler-echocardiography ${ }^{8}$ \\
Myocarditis & 40 & Necropsy ${ }^{25}$ \\
Verruacous endocarditis & $15-60$ & Necropsy ${ }^{25}$ \\
Pulmonary hypertension & 14 & Doppler-echocardiography ${ }^{34}$ \\
Myocardial infarction & $2-8$ & Clinic + ECG + enzymes ${ }^{42}$ \\
\hline
\end{tabular}

ciation between lupus carditis and antiphospholipid antibodies ${ }^{18-20}$, the pathogenesis of cardiac disease in SLE has not yet been clarified. The model traditionally considered for the pathogenesis of lupic carditis is quite similar to that of other sites of lupic involvement. It is based on the idea that a deposition of immune complexes and the activation of the complement lead to acute inflammation, chronic or recurrent in the vascular endothelium, pericardium, myocardium, endocardium, lead system and valvular leaflets, which may be supported by the common finding of immune complexes, complements and antinuclear antibodies in the affected tissues ${ }^{10}$. It is also possible that the immune complexes found in the tissues may not be pathogenic, but deposit there, passively, following a previous tissue lesion, in a way similar to the immunocomplexes found in the derma - epidermis junction of the normal skin of some patients with lupus ${ }^{21}$.

Moreover, it seems that heart disease in patients with lupus is found more commonly at autopsy than in clinical practice ${ }^{12}$. The pathological findings usually observed on necropsy of patients who died of SLE is pancarditis, affecting the pericardium, myocardium, endocardium and coronary arteries. The involvement of one layer of the heart, for example the pericardium, may be predominant in one individual but in another the heart may be diffusely affected.

\section{Pericarditis}

Pericarditis is the most common form of cardiac involvement in $\mathrm{SLE}^{8,12,17}$. In a similar way to other forms of cardiac involvement in lupus, its prevalence is also greater in autopsy samples, thus indicating that asymptomatic pericardial involvement is quite common ${ }^{8}$. Evaluating several clinical studies in the literature, Doherty and Siegel ${ }^{16}$ found a 25.6\% prevalence of pericarditis in 1,194 patients with SLE, but a prevalence of $62.1 \%$ in the 254 cases at autopsy. Bulkley and Roberts ${ }^{6}$ reported a predominately fibrous cardiac involvement in 53\% of 36 patients with SLE who had been using corticosteroids and were autopsied.

The cardiac evaluation in patients with SLE may quite frequently show pericarditis that varies from $24 \%$ to $49 \%{ }^{8}$. A great amount of the pericarditis may - consist of small effusions in asymptomatic patients ${ }^{22}$.

Acute pericarditis, with or without effusion, may be the initial manifestation of SLE and during the active stage of this condition, the hypothesis of lupus must always be considered, especially in women ${ }^{8}$. The clinical presentation of SLE is usually typical and includes fever, tachycardia, substernal pain (which worsens during breathing, coughing or leaning forward), and by the presence of pericardial attrition on auscultation. The ECG evaluation shows peaked T waves and elevation of the ST segment which is not different from that seen in other causes of pericarditis ${ }^{8,10.12}$. The inflammation may reach the sinoatrial node or the atrioventricular node and provoke arrhythmias ${ }^{23}$.

The pericardial fluid of patients with SLE frequently contains lupus erythematosus cells and low complement levels compared with that found in serum ${ }^{12,17}$. Antinuclear antibodies, anti-DNA antibodies, and rheumatic factor may also be found in the pericardial effusion ${ }^{16}$. The eventual finding of antinuclear antibodies is considered virtually pathognomonic of pericarditis associated with SLE ${ }^{10}$.

M-mode and two-dimensional echocardiography are currently considered the main complementary methods used for the diagnosis of pericardial effusion. However, the absence of pericardial effusion on echocardiography should not exclude the possibility of a clinically suspected pericarditis ${ }^{10}$.

In the cases of pericardial constriction, computerized tomography (CT) and magnetic resonance imaging (MRI) are superior to echocardiography for the visualization of pericardial thickening and of the calcifications ${ }^{10}$. However, in spite of the high frequency of pericarditis and effusion, cardiac tamponade and pericardial constriction rarely occur during the evolution of SLE ${ }^{8,12,17}$.

For symptomatic patients with a small effusion, treatment should include the use of nonsteroidal anti-inflammatory drugs, such as indomethacin with or without antimalarial medication. For the more severe cases, or those that do not respond to the above measures, usually steroids are used in dosages that vary from $0.5-1 \mathrm{mg} / \mathrm{kg} /$ day of prednisone, according to the seriousness of the involvement. Pericardial drainage and pericardiectomy rarely need to be performed $^{8,10,12,21}$.

\section{Myocarditis and cardiomyopathy}

Myocardial disease in lupus has three separate causes: the first and most frequent is myocarditis, acute or chronic, which is the cause of a cardiomyopathy specific to lupus; the second is myocardial ischemia, caused by coronary arteritis, coronary atherosclerosis, thrombosis or coronary embolism; the last cause is myocardial dysfunction resulting from mitral or aortic regurgitation ${ }^{10}$.

The recognition of myocardial involvement as a result of SLE has been considerably enhanced as a result of the hemodynamic and echocardiographic findings of systolic and diastolic dysfunction, in several patients with lupus who did not show clinical evidence of heart disease ${ }^{16,21}$.

As a matter of fact, primary myocardial involvement in lupus has not been considered common, because on clinical examination it has a frequency of only $8-10 \%^{8}$. However, a greater frequency of myocarditis of $40 \%{ }^{16}$ up to $80 \%{ }^{10}$ is observed on autopsy. The lower frequency of myocarditis in a series of necropsies more recently studied may be attributed to the greater use of steroids in patients with SLE ${ }^{21}$. 
Endomyocardial biopsies performed in patients with lupic myocarditis usually show accentuated interstiticial lymphocitic infiltration and perivascular tissue fibrosis, and the casual immunocomplex deposits in the myocardial vessels strongly suggest its part in inducing myocardial lesions ${ }^{24}$. Antimyocardial antibodies are observed, in variable frequency usually described as high, in the serum of patients with SLE. However, the role of these antibodies in cardiac involvement in the disease is not quite clear ${ }^{8,16}$.

The clinical identification of lupic myocarditis may be more difficult due to the frequent occurrence in SLE of other factors potentially responsible for myocardial damage, such as anemia, hypertension, systemic infection, valvular disease, water retention related to renal disease or the use of steroids. Patients who present with acute myocarditis usually have associated pericarditis. They also frequently have fever and tachycardia, which may be disproportionate to fever and thoracic pain. Such patients may only occasionally have signs of heart failure, arrhythmias, electrical conduction disorder, and intraventricular or atrioventricular blocks ${ }^{8,10,21}$.

Thus ventricular dysfunction caused by lupic myocarditis usually is not of a great magnitude, and therefore the so-called lupic cardiomyopathy is of high intensity rarely with symptoms and sometimes even without symptoms ${ }^{10,23}$. Cardiac failure may occur occasionally, mostly in association with severe dilated cardiomyopathy, this resulting from isolated myocarditis, or of several repeated episodes of myocarditis ${ }^{10}$. However, congestive heart failure, as an independent event, is reported in less than 5\% of lupic patients, which makes it secondary in importance to hypertension, sometimes resulting from use of steroids ${ }^{21}$.

On the other hand, asymptomatic lupic myocardial dysfunction seems to be a frequent occurrence, and as such, the detection of lupic cardiomyopathy usually depends on complementary diagnostic methods, such as cardiac catheterization ${ }^{16}$ or noninvasive methods such as two-dimensional Doppler echocardiography and radionuclide ventriculography ${ }^{25}$, which have a sensitivity similar to angiography and are currently are preferred.

In general terms, the electrocardiogram, which can show atrial and ventricular premature beats with nonspecific alterations in the ST segment and T waves and the chest X-ray, which only in cases of severe systolic dysfunction shows enlargement of the cardiac silhouette, have low-specificity in lupic myocarditis, usually producing results similar to those of other causes of cardiomyopathy. An increase in muscle enzymes may be present in patients with lupic carditis, which is a condition eventually associated with peripheral myositis, where the dosage of total creatine phosphokinase (CPK) and the muscle - brain fraction of creatine phosphokinase (CK - MB) in these patients would certainly be useful ${ }^{26}$.

The acute lupic myocarditis with serious clinical and hemodynamic involvement is treated with a high dosage of prednisone $(1 \mathrm{mg} / \mathrm{kg} / \mathrm{day})$. A minimum 7 - 14 days of treatment is recommended. Diuretics, vasodilators and digitalis can be used ${ }^{10}$. Immuno-suppression agents, such as azathioprine and cyclophosphamide have also been occasionally used ${ }^{8}$.

\section{Libman - Sacks endocarditis and valvular heart disease}

Libman - Sacks endocarditis (atypical verrucous endocarditis, noninfectious) is considered characteristic, even pathognomonic, finding of SLE. The name refers to verrucous vegetation, usually ranging in diameter from 1 $4 \mathrm{~mm}$. This vegetation can be found isolated or in conglomerates, usually strongly adhered to the endocardium of valve superficies, but also to chordae tendineae, papillary muscles and the atrial walls or ventricular endocardium. The four heart valves may be involved, the most common site being on the mitral valve (posterior leaflet), and the second most common site on the aortic valve 8,10,12,16. $^{\text {. }}$

Microscopic examination of the lesions shows degenerative cells, fibrin, fibrous tissue and occasionally hematoxylin corpuscles with a variable degree of inflammation. The observation of immunoglobulins and complements on the vessel walls of verrucous lesions suggests the presence of circulating immunocomplexes in the growth and proliferation of vegetation ${ }^{8,16}$.

Libman - Sacks endocarditis is primarily an anatomopathological not a clinical finding ${ }^{22}$. The lesions in this type of involvement are usually silent, and the occasional clinical problems associated with them are related more to embolic phenomenon or overlaying valvular dysfunction or heart failure ${ }^{9,23}$. The real prevalence of this type of involvement is hard to determine during clinical examinations alone, considering the fact that most of the murmurs heard on auscultation in lupus, which usually result from fever, anemia, tachycardia and cardiomegaly, are not associated with organic valvular disease ${ }^{9,16,22,25}$.

On the other hand, Libman - Sacks endocarditis is frequently reported on necropsies of patients who had no indication of murmurs during clinical examination. In regard to the prevalence of this type of lesion in necropsies of patients with SLE, the range of occurrence is reported to be from $15-60 \%{ }^{25}$ or from $13-74 \%{ }^{8}$.

The cardiac vegetations, usually small, are difficult to detect on echocardiogram, although this method might be useful when the vegetations are larger than $2 \mathrm{~mm}^{21}$. Vegetations of $10 \mathrm{~mm}$ in diameter or larger may be found in some patients with Libman - Sacks endocarditis ${ }^{16}$.

The incidence of this type of endocarditis has progressively declined during the last four decades, because of the use of more efficient therapeutics for SLE in recent years, compared with the initial period of 1920 and 1930 when the lesions were first described ${ }^{22}$. Corticosteroids' specific mechanism of action is controversial. Some people attribute the possible reduction in the incidence of these lesions in lupus to an increase in corticoid use ${ }^{16}$. Also attributed to steroids is a possible reduction in valvular dysfunction, because they promote healing of scars caused 
by veruccous lesions, which would result in fibrotic retraction of valval cuspides ${ }^{6,7,21}$.

Another possible explanation for the lower frequency of verrucous endocarditis described in recent years is that the diagnosis of SLE is now carried out before death through clinical criteria, and not by the postmortem finding of cardiac vegetations, as in the past, when the recognition of the high specificity of the lesions and the absence of other diagnostic criteria for SLE stimulated a search for them on necropsies ${ }^{8,16}$ Although Libman - Sacks endocarditis rarely results in considerable hemodynamic involvement, some complications, such as rupture of the chordae tendineae, aortic stenosis, localized thrombosis and cerebral embolism, are reported ${ }^{8}$. Infectious endocarditis may complicate Libman - Sacks endocarditis. Doherty and Siegel ${ }^{16}$ demonstrated this in a meta-analysis of 15 reports showing that $4.9 \%$ of cases of verrucous endocarditis identified at necropsy and $33 \%$ of cases clinically diagnosed had infectious endocarditis as a complication. Such frequencies are greater than in the general population or even in patients with other diseases of the connective tissue. Therefore, the prophylactic use of antibiotics in dental and surgical procedures is indicated in patients with Libman - Sacks endocarditis ${ }^{21}$.

Valvular thickening, whether or not due to Libman Sacks endocarditis, visualized with M-mode or twodimensional echocardiography may be observed in about half of patients with SLE. Valvular thickening predominantly occurs in the mitral and aortic valves ${ }^{10}$, and may, in some cases, be correlated with surgical findings of verrucous endocarditis ${ }^{21}$.

The most common valvular dysfunction in lupus is regurgitation, which in most cases is of small magnitude with no clinical significance. However, valvular malfunction, with considerable clinical, and hemodynamic importance to an extent where they require surgical replacement by prosthesis may occur in certain patients ${ }^{8}$. Aortic regurgitation, which may result from Libman - Sacks endocarditis, valvulitis, fibrosis, mucous degeneration, bacterial endocarditis and aortic dissection, is considered to be the valve dysfunction usually associated with severe hemodynamic importance in SLE ${ }^{16}$.

Severe cases of mitral regurgitation have also been reported, however less frequently. Mitral regurgitation may be caused by fibrosis, thickening and calcification of the mitral leaf and chordae tendineae, rupture of the chordae tendineae, and fibrinoid necrosis of papillary muscles. Cases of aortic stenosis, mitral stenosis, and tricuspid stenosis resulting from in situ thrombosis, some requiring valve replacement, have also been described, however in limited numbers ${ }^{8,10,16}$.

The valvular evaluation in lupus includes the conventional findings of clinical examination and electrocardiogram, chest X-ray and echocardiogram. The transthoracic echocardiography is presently the method most used for diagnosis of valvular disease associated with SLE ${ }^{10}$. The transesophageal echocardiogram is also beginning to be used as much in clinical evaluations as in studies for evaluation of the frequency of valvular involvement in lupus. Roldan et al ${ }^{27}$ found a $74 \%$ frequency of valvular involvement in SLE using this method. A greater frequency of regurgitation in the right chambers in relation to the left chambers, as identified in patients with SLE through Doppler echocardiography, has been associated with pulmonary vascular lesions, resulting in pulmonary hyperten$\operatorname{sion}^{8,22}$.

At this time, not enough data are available that indicate that stenoids or other immune suppression therapy is beneficial in the treatment of valvular involvement associated with SLE. Valve replacement has regularly been indicated in patients with symptomatic valve disease and with clinical and hemodynamic ${ }^{7,28,29,30}$, although morbidity associated with valve replacement in patients with lupus has been considered twice as high as in patients without lupus ${ }^{10}$, being closely linked to acute renal failure ${ }^{7,28}$. Recently, Morin et al $^{31}$ reviewed 25 cases of mitral failure secondary to SLE requiring valve replacement. They observed postoperative mortality and suggest that the surgical risks for these patients seems to be the same as that for the population without lupus, but may be considerably higher only in older patients and in others where the disease acutely affects other organs, mainly the kidneys.

\section{Pulmonary hypertension}

Association of pulmonary hypertension with diseases of the connective tissues has been most frequently described in the combination of connective tissue disease and systemic sclerosis, this last especially in CREST syndrome (calcinosis, Raynaud's phenomenon, sclerodactyly, esophageal involvement and telangiectasia) ${ }^{32}$. Although acute pulmonary arterial hypertension continues to be considered a rare manifestation, it has been demonstrated to be common in patients with subclinical or mild cases of SLE, and a current trend exists to recognize pulmonary arterial hypertension as a complication of SLE ${ }^{21,33}$.

The determination of the real prevalence and magnitude of pulmonary hypertension in SLE has been difficult over the years due to the fact that the only method with sufficient sensitivity for determining pulmonary pressures and confirming the existence of pulmonary hypertension has been the catheterization of the right chambers with direct measurement of pulmonary pressures ${ }^{34}$, an invasive method that one is naturally reluctant to use before symptoms and signs of advanced disease are -present. In fact, in older reports a trend can be observed of studying patients with SLE with well defined clinical manifestation of pulmonary arterial hypertension ${ }^{35-38}$, which usually is associated with high pressure levels in the pulmonary artery. Thus, the study of pulmonary artery hypertension at one time was limited to patients with symptoms, who had advanced forms of pulmonary arterial hypertension - a situation in which the data obtained by catheterization of the right cardiac chambers usually are less useful for diagnosis than for prognosis, because the existence of pulmo- 
nary artery hypertension, as a rule, is detected by clinical finding, electrocardiograph and conventional radiographs.

The advent of two-dimensional Doppler echocardiography, a method thought to be of similar sensitivity as right chamber catheterization for measuring pulmonary pressure, allowed the study of a greater number of patients, with or without symptoms. Simonson et al ${ }^{34}$, by way of Doppler echocardiography, found a frequency of pulmonary artery hypertension (defined as systolic arterial pressure $>30 \mathrm{mmHg}$ ) of $14 \%$ in 36 patients with SLE, observing in these patients a slight increase pulmonary pressures, suggesting that pulmonary arterial hypertension in SLE is common, although of light intensity. A gradually progressive pulmonary hypertension in lupus was demonstrated by Winslow et $\mathrm{al}^{39}$, when reevaluating this same group of patients five years later and concluding that the prevalence of pulmonary hypertension increased from $14 \%$ to $43 \%$.

Although several mechanisms are involved in its pathogenesis, the real causes of pulmonary hypertension in SLE are yet unknown. The hypothesis of pulmonary vasculitis, with deposits of immunocomplexes and complements on the pulmonary artery walls, thromboembolic blockage in pulmonary vessels, possibly related to antibodies, and vasospasms, are suggested by a greater frequency of Raynaud's phenomenon in these patients ${ }^{21,33,34,40 .}$

In lupus, the rare forms of pulmonary arterial hypertension produce symptoms that usually develop insidiously and gradually progress. Dry cough, thoracic pain and shortness of breath are usually the first symptoms, which may not be noticed because the physical examination and chest X-ray are frequently normal during the initial phase. Later, the second heart sound in the pulmonary area intensifies, and X-ray of the thorax shows an enlargement of the pulmonary vessels. The electrocardiogram shows overload of the right chambers. At this point, the Doppler echocardiography or catheterization of the right chamber clearly shows pulmonary hypertension ${ }^{33,41}$.

The prognosis for the acute form of the disease is somber. More than $50 \%$ of the patients die within a period of two years. A large number of the patients reported here have undergone treatment with vasodilators, anticoagulants, corticoids and cytotoxic agents, and in spite of several reports of improvement of the symptoms, the hemodynamic response has generally been unsatisfactory. Support therapy with oxygen supplementation, diuretics and anticoagulation is indicated for those with cardiac failure. The joint heart-lung or lung only transplant has been carried out with success in some patients ${ }^{33,41}$.

\section{Coronary disease and myocardial infarction}

Two main mechanisms are involved in the pathogenesis of coronary disease in patients with lupus: atherosclerosis, which is the more common pathological process, usually accelerated by the continued use of steroids, and coronary vasculitis, which is rare ${ }^{8}$. Similarly to what occurs in the general population, in this group of patients hyper- tension, smoking, cholesterol levels above $200 \mathrm{ml} / \mathrm{dL}$ and obesity have equally been considered important coronary risk factors ${ }^{10,16,21,23}$. In rare cases, acute coronary obstruction may be caused by embolism resulting from Libman Sacks endocarditis, an intracoronary in situ thrombosis or a vasospasm ${ }^{10,12}$.

Although in the period prior to the use of corticosteroids, coronary disease was considered rare in lupus, the incidence of ischemic heart disease in this illness has clearly increased in the past few years ${ }^{8,12,16,21}$. Coronary atherosclerosis has accelerated in patients with SLE who receive corticosteroids over long periods. Bulkley and Roberts ${ }^{6}$ observed more than $50 \%$ coronary obstruction in a frequency of $42 \%$ in necropsies of lupus patients who used steroids for longer than 12 months. However, no more than a $50 \%$ coronary obstruction was found in patients who received steroids for less than 12 months.

Although traditionally considered of relatively low frequency in lupus (around 2 - $8 \%$ according to Asherson and Cervera ${ }^{42}$ ) myocardial infarction has been progressively emphasized as a common cause of death in patients with SLE, noticeably in death occurring after 10 - 30 years of evolution of the illness ${ }^{22}$. Sudden death, however, is considered an uncommon event in $\mathrm{SLE}^{23}$.

Farhey and Hess ${ }^{43}$ report that the percentile values between $6.1 \%$ and $8.9 \%$ observed in several studies to determine the prevalence of angina or myocardial infarction in SLE, are probably underestimates of the true prevalence of coronary disease in this condition, as tests with thallium201perfusion scintigraphy demonstrated anomalies in $38.5 \%$ of patients and necropsy reports confirmed coronary disease of $22-55 \%$.

Immunoglobulins and components of the complement system have been identified on coronary arterial wall of patients with coronary vasculitis. It has been suggested that the vascular lesions measured immunologically also may be responsible for subsequent development of atherosclerosis ${ }^{8}$. Such an idea may be reinforced by a greater frequency of pericardial and valvular involvement found in lupus patients with serious atherosclerotic lesions, which once again suggests a possible contribution of immunologic factors to the resulting of coronary disease in these patients ${ }^{8,16,21}$.

The presence of coronary involvement in SLE usually is nonspecific, fundamentally covering the classic factors of effort angina, unstable angina, transmural and nontransmural myocardial infarction, eventually leading to heart failure secondary to left ventricular dysfunction due to ischemia. The classic tests used for coronary disease evaluation are the electrocardiogram, treadmill stress test (with or without scintigraphy). The echocardiogram and the coronary angiography may be used in patients with SLE, providing a diagnostic value quite similar to that of the general population ${ }^{10}$. The use of ionic contrasts may complicate the evaluation of lupic heart disease, leading to acute renal failure, which must be considered when deciding the need for diagnostic investigation with angiography. 
Although, coronary arteritis may be much less frequent than atherosclerosis as a cause of coronary disease in patients with SLE, only a few cases have been adequately documented. The clinical distinction between the two processes is important, as high dosages steroids may be indicated in patients with coronary vasculitis and may be potentially deleterious, at least for the long-term use, in patients with atherosclerosis ${ }^{21}$. None of the diagnostic techniques, however, including angiography, have been shown capable of clearly differentiating arteritis from coronary atherosclerosis ${ }^{10}$, although angiographic findings of flat lesions, aneurysmal dilatations, and abrupt passage from normal flow to grave obstruction, may suggest arteritis ${ }^{8}$.

At any rate, if coronary arteritis is suspected, high dosages of steroids (prednisolone, $1 \mathrm{mg} / \mathrm{kg}$ day or more) should be prescribed for a period not yet clearly defined, emphasizing that use of corticotherapy in cases of recent myocardial infarction in lupus patients is controversial due to the possible greater risk of myocardial rupture ${ }^{10}$. Except for the use of corticosteroids in cases of arteritis, the therapeutic approach to coronary disease in SLE is similar to that used in patients in the general population, but here extra care should be taken with lupic patients for secondary or even primary prevention of coronary disease, using diet, cholesterol-lowering drugs, smoking cessation programs, aggressive treatment of arterial hypertension and tentative reduction of corticosteroid dosages ${ }^{43}$. Although some have preferred the use of nifedipine in lupus patients, due to the possibility of association of coronary disease with Raynaud's phenomenon and vasospams ${ }^{22}$, other coronary vasodilators may normally be used. The use of ACE inhibitors may not be possible in some patients, due to renal failure ${ }^{22}$. Angioplasty and myocardial revascularization surgery have been employed ${ }^{10,12,16}$ with several reports of satisfactory results.

\section{Antiphospholipid antibodies (aPLs) and the heart in lupus}

Antiphospholipid antibodies (aPLs) are most commonly identified through coagulation tests. They have been associated with thrombotic manifestations, low platelet counts and miscarriages as frequently in patients with SLE as in a variety of situations, such as connective tissue diseases, patients with neoplasia, acquired immunodiciency syndrome, the use of certain drugs (phenytoin, interferon, quinidine, cocaine) or even with no identifiable illness ${ }^{44,45}$.

aPLs were identified in 1952 when Conley and Hartman discovered a coagulation inhibitor in lupic patients, named lupus anticoagulant $(\mathrm{LA})^{46}$. Later on it was discovered that the coagulation inhibitor came from the immunoglobulins IqA, or IqM, or perhaps both of these directed against the natural phospholipids in the coagulation cascade, and also that the hemorrhagic disturbances were not frequent. In fact a paradoxical increase in thrombosis in patients with LA occured, by mechanisms not yet well explained, but which may include a lesion of the endothelium by aPLs ${ }^{47,48}$. On the other hand, it was also observed that the LA was frequently associated with the presence of false-positive serum tests for syphilis, which also commonly occurs in lupus patients ${ }^{46}$.

Based on this observation cardiopin, a phospholipid originally extracted from bovine hearts and used for serum tests for syphilis, was introduced as an antigen in solid phase immunology studies, such as radioimmunossay and enzyme-linked immunosorbent assay (ELISA) ${ }^{46}$. Presently, ELISA is the most commonly used method for the research on aPLs and for the detection of anticardiolipin antibodies (aCL) of the IgM, IgG, or IgA type, or all of these.

During the past years, a great spectrum of cardiac involvement has been reported in several types of patients with aPLs ( table II), which suggests the possibility of aPLs also being responsible for the basic immunological events related to the onset of heart disease, and that certain cardiac manifestations may, in fact, be part of the primary or secondary so-called antiphospholipid antibody syndrome (aPL syndrome) defined as a set of clinical manifestations associated with the presence of these antibodies ${ }^{42}$.

Although some authors have not found any association between cardiac manifestation in lupus and the presence of aPLs ${ }^{27,49,50}$ other authors demonstrate a significant frequency of aPLs in lupic patients with different forms of cardiopathy. Among cardiac manifestations of SLE Libman - Sacks endocarditis and especially valvular defects and valvular thickening are the most frequently reported as being associated with aPLs ${ }^{18,19,20,51,52}$.

These findings have been reinforced by the fact that valvular lesions similar to those found in lupus have been found in patients with primary aPL syndrome ${ }^{42}$. Whether the aPLs are the cause of valvular lesions, or simple coincidence accompanied by other immunological disorders, is not known. The findings of selective immunoglobulin deposits and complements along with cardiac vegetations in patients with Liebman - Sacks endocarditis, suggesting involvement of a part of the immune complexes in the onset and growth of the lesions ${ }^{42}$, should be emphasized, however, as should the more recent and suggestive findings of anticardiolipin antibody deposits in the subendothelial layer of valves in patients with aPL syndrome ${ }^{53}$.

Table II - Cardiovascular manifestations possibly associated with antiphospholid antibodies

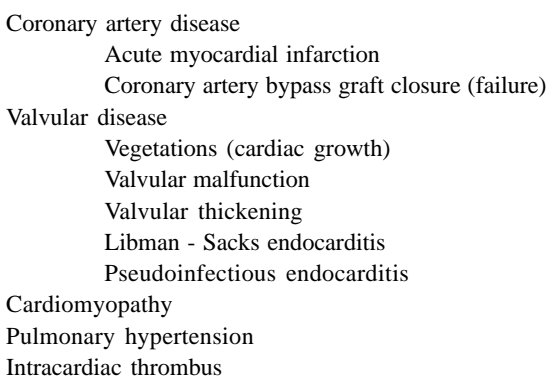


Several cases of myocardial infarction have been documented in patients with primary aPL syndrome or aPL associated with lupus ${ }^{53}$. The antiphospholipid antibodies may in this way become additional risk factors for coronary disease in patients with SLE, in addition to arteritis and classic precocious artherosclerosis ${ }^{42}$. The observation that antibodies against low density lipoproteins (LDL), which are also considered antiphospholipid antibodies due to the presence of phospholipids and apolipoprotein B in the LDL molecules have been found to be more clearly associated to with atherosclerotic phenomenon than with the thrombotic phenomenon itself, which suggests the interesting possibility of aPLs being directly responsible for the development of atherosclerosis in patients with SLE ${ }^{54}$.

Some evidence of the possible relation between the aPLs and myocardial infarction is also reported in studies of patients who do not have SLE or aPL syndrome. Hamsten et al ${ }^{55}$ evaluated 62 survivors of a first myocardial infarction, less than 45 years old, and found high levels of anticardiolipin (aCL) in 13 (21\%). Eight of the 13 patients with aCL levels persistently high experienced additional cardiovascular events during a 36 - 64 month follow-up, which suggests that aCL should be interpreted as a risk factor for recurrent cardiovascular events after the first myocardial infarction. Morton et al ${ }^{56}$ over 12 months observed the evolution of 83 patients who had coronary artery bypass grafts and found that high levels of aCL were related to a significant incidence of late occlusion of the graft.

More recently, Zuckerman et al. ${ }^{57}$ evaluated 124 nonlupic patients less than 65 years old who survived an acute myocardial infarction, and similarly observed that the incidence of thromboembolic events and reinfarction during a variable follow-up period of 12 to 27 months was significantly higher in patients positive for anticardiolipin antibodies.

Pulmonary hypertension in SLE has also been associated with the presence of aPLs. Asherson et al. ${ }^{58}$ found a frequency of aPLs of $68 \%$ in 24 patients with pulmonary hypertension, 22 of these with SLE one with primary aPL and one with overlaying SLE/sclerodermatis syndrome. Miyata et al ${ }^{53}$ studied a correlation between aCL levels and the degree of pulmonary hypertension in a group of 22 patients who presented with mixed diseases of the connec- tive tissue or SLE and found a significant correlation between the aCL levels and the mean pulmonary pressure of patients with mixed diseases of the connective tissue.

Myocardial dysfunction has been significantly associated with the presence of aPLs in at least one study. Leung et al ${ }^{19}$ evaluated 75 patients with SLE by Doppler echocardiography, ELISA for aCL and various tests for LA and concluded that of five patients with myocardial dysfunction, four $(80 \%)$ were positive for aPLs $(p<0.05)$. Thrombotic closures of the myocardial microcirculation, in the absence of vasculitis (cardiac microvasculopathy), may be a possible explanation for this type of anomaly in patients with aPLs ${ }^{42,53}$.

Other cardiac manifestations in lupus, such as pseudoinfectious endocarditis - which is a type of acute thrombosis of Libman - Sacks endocarditis, related to periods of activity of SLE with clinical findings quite similar to those of bacterial endocarditis - and the intracavity thrombus, have also been associated with the presence of aPLs ${ }^{42,53}$, which correlates with a greater frequency of cerebral, ischemic events found in patients with aPLs.

\section{Conclusion}

The usual combination of multiple clinical problems in patients with lupus, which usually includes simultaneous multiple organ involvement and several infections, may make it difficult to detect cardiac involvement in SLE, which is not always easy to identity during clinical evaluation. Moreover, the high frequency of cardiac disorders in SLE may also occur independently of the markers of lupic activity ${ }^{50.60}$ justifies a high degree of suspicion about the existence of heart disease in the routine evaluation of all patients with the disease.

The antiphospholipid antibodies known to be involved in several clinical manifestations of SLE ${ }^{61,66}$ may also be associated with several modes of cardiac involvement in this condition. A series of studies, which has as its objective evaluation of the existence of this association, may contribute to the elaboration of new pathogenic models related to cardiovascular disease and to other important effects of SLE.

\section{References}

1. Klippel JH, Decker JL. Systemic lupus erythematosus. In: Stein JH, et al (eds) Internal Medicine, $2^{\text {nd }}$ ed. Boston/Toronto: Little, Brown and Company 1987; pp.1270-8.

2. Pisetsky DS, Gilkeson G, St Clair W. Systemic lupus erythematosus - Diagnosis and treatment. Med Clin North Am 1997; 81: 113-28.

3. Talbott JH. Historical background of discoid and systemic lupus erythematosus. In: Wallace DJ, Hahn BH. (eds) - Dubois' Lupus Erythematosus. $4^{\text {th }}$ ed. Malvern: Lea \& Febiger 1993; pp. 3-10

4. Klippel JH. Systemic Lupus Erythematosus: Demographics, Prognosis and Outcome. J Rheumatol 1997; 24(suppl. 48): 67-71.

5. SchurPH.Systemiclupuserythematosus. In: Bennet JC,PlumF. (eds)-Cecil Textbook of Medicine. 20 ${ }^{\text {th }}$ ed. Philadelphia: WB Saunders Company 1996; pp. 1475-83.
6. Bulkley HB, Roberts WC. The heart in systemic lupus erythematosus and the changes induced in it by corticosteroid therapy - a study of 36 necropsy patients. Am J Med 1975; 58: 243-64.

7. Dajee H, Hurley EJ. Szarnicki RJ. Cardiac valve replacement in systemic lupus erythematosus - A review. J Thorac Cardiovasc Surg 1983; 85: 718-26.

8. Quismorio Jr FP. Cardiac abnormalities in systemic lupus erythematosus. In: Wallace DJ, Hahn BH. (eds) - Dubois' Lupus Erythematosus. $4^{\text {th }}$ ed. Malvern: Lea \& Febiger 1993; p.p. 332-42.

9. Stevens MB. Lupus carditis. N Engl J Med 1988; 319: 861-2

10. Roldan CA, Crawford MH. Connective tissue diseases and the heart. In: Crawford MH. (ed) - Current Diagnosis \& Treatment in Cardiology. Rio de Janeiro: Prentice Hall do Brasil 1995; pp. 428-47. 
11. Castier MB, Meneses ME, Albuquerque EM, et al. O envolvimento cardíaco no lúpus eritematoso sistêmico. Uma avaliação eletrocardiográfica. Arq Bras Cardiol 1994; 62: 407-12.

12. Coblyn JS, Weinblat ME. Rheumatic diseases and the heart. In: Braunwald E. (ed) Heart Disease. $5^{\text {th }}$ Ed. Philadelphia: WB Saunders Company 1997; 1776-83.

13. Osler W. On the visceral complications of the erythema group of skin diseases [third paper]. Ann J Med Sci 1904; 127: 1-23.

14. Libman E, Sacks B. A hitherto undescribed form of valvular and mural endocarditis. Arch Int Med 1924; 33: 701-37.

15. Gross L. The cardiac lesion in Libman-Sacks disease with a consideration of its relationship to acute lupus erythematosus. Am J Pathol 1940; 16: 375.

16. Doherty NE, Siegel RJ. Cardiovascular manifestations of systemic lupus erythematosus. Am Heart J 1985; 110: 1257-65.

17. Lahita RJ. Clinical presentation of systemic lupus erythematosus. In: Kelley WN, et al (eds) - Textbook of Rheumatology. $5^{\text {th }}$ ed. Philadelphia: WB Saunders Company 1997: 1028-39.

18. Cervera R, Font J, Paré C, et al. Cardiac disease in systemic lupus erythematosus: prospective study of 70 patientes. Ann Rheum Dis 1992; 51: 156-9.

19. Leung WH, Wong KL, Lau CP, et al. Association between antiphospholipid antibodies and cardiac abnormalities in patients with systemic lupus erythematosus. Am J Med 1990; 89: 411-9.

20. Nihoyannopoulos P, Gomez PM, Joshi J, et al. Cardiac abnormalities in systemic lupus erythematosus: Association with raised anticardiolipin antibodies. Circulation 1990; 89: 369.

21. Carette $S$. Cardiopulmonary manifestations of systemic lupus erythematosus Rheum Dis Clin North Am 1988; 14: 135-47.

22. Rothfield NF. Cardiac aspects. In: Schur PH. (ed) - The Clinical Management of Systemic Lupus Erytemathosus. $2^{\text {nd }}$ ed. Philadelphia: Lippincott-Raven 1996: 83-93.

23. Kim MH, Abrams GD, Pernicano PG, et al. Sudden death in a 55-year-old woman with systemic lupus erythematosus. Circulation 1998; 98: 271-5.

24. Bidani AK, Roberts JL, Schwartz MM, et al. Immunopathology of cardiac lesions in fatal systemic lupus erythematosus. Am J Med 1980; 69: 849-58.

25. Gladman DD, Urowitz MB. Systemic lupus erythematosus - Clinical features. In Klippel JH, Dieppe PA. (eds) - Rheumatology $2^{\text {nd }}$ ed. London: Mosby, 1998; sec 7: 1.1-1.18.

26. Borenstein DG, Fye WB, Arnett FC, et al. The myocarditis of systemic lupus erythematosus. Ann Int Med 1978; 89(parte 1): 619-4

27. Roldan CA, Shively BK, Lau CC, et al. Systemic lupus erythematosus valve disease by transesophageal echocardiography and the role of antiphospholipid antibodies. J Am Coll Cardiol 1992; 20: 1127-34

28. Moyniham T, Hansen R, Troup P, et al. Simultaneous aortic and mitral valve replacement for lupus endocarditis: Report of a case and review of the literature. J Thorac Cardiovas Surg 1988; 95: 142-5.

29. Demircin M, Dogan R, Peker O, et al. Aortic insuficciency and enterococcal endocarditis complicating systemic lupus erythematosus. Thorac.cardiovasc. Surgeon 1995; 43: 302-4

30. Chauvaud S, Kalangos A, Berrebi A, et al. Systemic lupus erythematosus valvulitis: Mitral valve replacement with a homograft. Ann Thorac Surg 1995; 60: 1803-5.

31. Morin AM, Boyer AS, Nataf P, et al. Mitral insufficiency caused by systemic lupus erythematosus requiring valve replacement: three case reports and a review of the literature. Thorac. cardiovasc. Surgeon 1996; 44: 313-6.

32. Cervera R, Garcia-Carrasco M, Asherson RA. Pulmonary manifestations in the antiphospholipid syndrome. In: Asherson R, Cervera R, Piette J-C, et al. (eds) The Antiphospholipid Syndrome. Boca Raton: CRC Press 1996: 161-7.

33. Quismorio Jr FP. Pulmonary manifestations. In: Wallace DJ, Hahn BH. (eds) Dubois' Lupus Erythematosus. $4^{\text {th }}$ ed. Malvern: Lea \& Febiger 1993: 343-55.

34. Simonson JS, Schiller NB, Petri M, et al. Pulmonary hypertension in systemic lupus erythematosus. J Rheumatol 1989; 16: 918-25.

35. Gladman DD, Sternberg L. Pulmonary hypertension in systemic lupus erythematosus. J Rheumatol 1985; 12: 365-7.

36. Nair SS, Askari AD, Popelka CG, et al. Pulmonary hypertension and systemic lupus erythematosus. Arch Int Med 1980; 140: 109-11.

37. PerezDH,KramerN.Pulmonary hypertension in systemic lupus erythematosus: report of four cases and review of the literature. Sem Arthritis Rheum 1981;11: 177-81.
38. Wohl MJ. Case Records of the Massachusetts General Hospital (Case 4-1973) N Engl J Med 1973; 288: 204-10.

39. Winslow TM, Ossipov MA, Fazio GP, et al. Five-year follow-up study of the prevalence and progression of pulmonary hypertension in systemic lupus erythematosus. Am Heart J 1995; 129: 510-5.

40. Asherson RA, Oakley CM. Pulmonary hypertension and systemic lupus erythematosus. J Rheumatol 1986; 13: 1-5.

41. Medsger Jr. TA. Pulmonary manifestations. In: Schur PH. (ed) - The Clinical Management of Systemic Lupus Erythematosus. $2^{\text {nd }}$ ed. Philadelphia: Lippincott-Raven 1996: 87-93

42. Asherson RA, Cervera R. Antiphospholipids and the heart - Lessons and pitfalls for the cardiologist. Circulation 1991; 84: 920-3

43. Farhey Y, Hess EV. Accelerated atherosclerosis and coronary disease in SLE. Lupus 1997; 6: 572-7.

44. Bick RL, Kaplan H. Syndromes of thrombosis and hypercoagulability - Conge nital and acquired causes of thrombosis. Med Clin North Am 1998; 82: 409-58.

45. Bick RL. The antiphospholipid-thrombosis syndromes: fact, fiction, confusion and controversy. Am J Clin Pathol 1993; 100: 477-80.

46. Asherson RA, Cervera R, Piette JC, et al.. The antiphospholipid syndrome: history, definition, classification, and differential diagnosis. In: Asherson R, Cervera R, Piette JC, et al. (eds) - The Antiphospholipid Syndrome. Boca Raton: CRC Press 1996: 3-12

47. Tripplet DA, Brandt J. Laboratory identification of the lupus anticoagulant. Br J Haematol 1989; 73: 139-42.

48. Tripplet DA. New diagnostic strategies for lupus anticoagulants and antiphospholipid antibodies. Haemostasis 1994; 24: 155-64

49. Alves JA, Hydalgo L, Rolim LF, et al. Avaliação clínica e laboratorial d cardiopatia no lúpus eritematoso sistêmico. Arq Bras Cardiol 1997; 68: 79-83.

50. Ong ML, Veerapen K, Chambers JB, et al. Cardiac abnormalities in systemic lupu erythematosus: prevalence and relationship with disease activity. Int J Cardiol 1992; 34: 69-74.

51. Chartash EK, Lans DM, Paget SA, et al. Aortic insufficiency and mitral regurgitation in patients with systemic lupus erythematosus and the antiphospholipid syndrome. Am J Med 1989; 86: 407-12.

52. Khamashta MA, Cervera R, Asherson RA, et al. Association of antibodies against phospholipids with heart valve disease in systemic lupus erythematosus. Lancet 1990; 335: 1541-4.

53. Cervera R, Font J, Ingelmo M. Cardiac manifestations in the antiphospholipid syndrome. In: Asherson R, Cervera R, Piette JC, et al. (eds) - The Antiphospholipid Syndrome. Boca Raton: CRC Press 1996: 151-60.

54. Vaarala O. Antiphospholipid antibodies and atherosclerosis. Lupus 1996; 5: 442-7.

55. Hamstem A, Björkholm M, Norberg R, et al. Antibodies to cardiolipin in young survivors of myocardial infarction: an association with recurrent cardiovascular events. Lancet 1986; 1: 113-6.

56. Morton KE, Gavaghan TP, Krilis SA, et al. Coronary artery bypass graft failure an autoimune phenomenon? Lancet 1986; 1: 1353-7.

57. Zuckerman E, Toubi E, Shiran A, et al. Anticardiopin antibodies and acute myocardial infarction in non-systemic lupus erythematosus patients: a controlled prospective study. Am J Med 1996; 101: 381-6.

58. Asherson RA, Higenbottam TW, Dihn Xuan AT, et al. Pulmonary hypertension in a lupus clinic: experience with twenty-four patients. J Rheumatol 1990; 17: 1291-8.

59. Miyata M, Suzuki K, Sakuma F, et al. Anticardiolipin antibodies are associated with pulmonary hypertension in patients with mixed conective tissue disease or systemic lupus erythematosus. Int Arch Allergy Immunol 1993; 100: 351-4.

60. Roldan CA, Shively BK, Crawford MH. An echocardiographic study of valvular heart disease associated with systemic lupus erythematosus. N Engl J Med 1996; 335: 1424-30

61. Takahaski C, Kumagai S, Tsubata R, et al. Portal hypertension associated with anticardiolipin antibodies in a case of systemic lupus erythematosus. Lupus 1995; 4: 232-5

62. Galeazzi M, Bellisai F, Sebastiani GD, et al. Association of 16/6 and SA1 antiDNA idiotypes with anticardiolipin antibodies and clinical manifestations in a large cohort of SLE patients. Clin Exp Rheumatol 1998; 16: 717-20. 